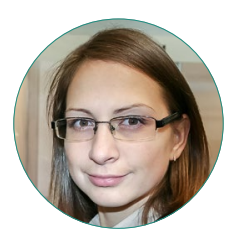

А. В. Каравай

\title{
ДЕЙСТВИЯ РОССИЯН ПО УЛУЧШЕНИЮ СОБСТВЕННОГО МАТЕРИАЛЬНОГО ПОЛОЖЕНИЯ В ЭПОХУ COVID-19
}

\section{Правильная ссылка на статью:}

Каравай А.В. Действия россиян по улучшению собственного материального положения в эпоху COVID-19 // Мониторинг общественного мнения: экономические и социальные перемены. 2021. № 2. С. 121-137. https://doi.org/10.14515/monitoring.2021.2.1837.

\section{For citation:}

Karavay A. V. (2021) The Behavior of Russians Aimed at Improving Their Financial Situation in the Era of COVID-19. Monitoring of Public Opinion: Economic and Social Changes. No. 2. P. 121-137. https://doi.org/10.14515/monitoring.2021.2.1837. (In Russ.) 
ДЕЙСТВИЯ РОССИЯН ПО УЛУЧШЕНИЮ СОБСТВЕННОГО МАТЕРИАЛЬНОГО ПОЛОЖЕНИЯ В ЭПОХУ COVID-19

КАРАВАЙ Анастасия Вадимовна - кандидат социологических наук, старший научный сотрудник, Институт социологии Федерального научно-исследовательского социологического центра Российской академии наук, Москва, Россия; старший научный сотрудник, Институт социальной политики, Национальный исследовательский университет "Высшая школа экономики", Москва, Россия E-MAIL: karavayav@yandex.ru

https://orcid.org/0000-0003-3122-4819

Аннотация. Исследование посвящено анализу действий россиян по улучшению своего материального положения в условиях экономического кризиса, вызванного пандемией коронавируса. Эмпирической базой выступили данные опросов Института социологии ФНИСЦ РАН за ряд лет, один из которых был проведен в сентябре 2020 г. В статье продемонстрированы изменения поведения россиян в условиях различных экономических кризисов, в частности сокращение популярности наиболее универсальных, сформировавшихся еще в 1990-е годы, способов улучшения своего материального положения, связанных со случайными заработками и подсобным хозяйством. Показано также, что, в отличие от кризиса 2014-2016 гг., в 2020 г. у многих ранее благополучных представителей массовых слоев общества произошло настолько серьезное сокращение источников доходов, что части из них пришлось изменить свое поведение и искать дополнительные способы поддержания материального положения. В результате среди представителей
THE BEHAVIOR OF RUSSIANS AIMED AT IMPROVING THEIR FINANCIAL SITUATION IN THE ERA OF COVID-19

Anastasia V. KARAVAY ${ }^{1,2}-$ Cand. Sci. (Soc), Senior Researcher; Senior Reseracher, Institute for Social Policy

E-MAIL: karavayav@yandex.ru https://orcid.org/0000-0003-3122-4819

\footnotetext{
1 Institute of Sociology of the Federal Center of the Theoretical and Applied Sociology of the Russian Academy of Sciences, Moscow, Russia

2 HSE University, Moscow, Russia
}

Abstract. The study analyzes the behavior of Russians aimed at improving their financial situation in the context of the economic crisis caused by the pandemic. The empirical base was the data of surveys conducted by the Institute of Sociology of the FCTAS RAS over a number of years, one of which was carried out in September 2020. The article demonstrates changes in the behavior of Russians in the context of various economic crises, in particular, the decline in the popularity of the most universal ways to improve their financial situation associated with odd jobs and subsidiary farming. It is also shown that in contrast to the crisis of 2014-2016, in 2020, many previously prosperous representatives of the mass strata of society experienced such a serious reduction in income sources that some of them had to change their behavior and look for additional ways to maintain their financial situation. As a result, representatives of the mass strata of the population began to more often turn to their close circle for help, and representatives of high-resource social groups began to practice 
массовых слоев населения стало шире распространено привлечение помощи от близкого окружения, а также действия, характерные для относительно высокоресурсных социальных группсовместительство, сверхурочная занятость, использование накопленных ранее материальных и финансовых активов. Однако собственных ресурсов даже у сравнительно благополучных представителей массовых слоев населения страны постепенно становится все меньше, а их наращивание в современных социально-экономических условиях затруднительно, поэтому для многих россиян единственной возможностью улучшения своего материального положения становится интенсификация занятости по найму. Однако внешним барьером для ее распространения оказывается ограниченность числа рабочих мест, предполагающих высококвалифицированный и высокооплачиваемый труд и/или оплату сверхурочной занятости.

Ключевые слова: адаптация, ресурсы населения, поведенческие паттерны, трудовые стратегии, влияние кризиса на общество, адаптационные стратегии

Благодарность. Исследование выполнено за счет гранта Российского научного фонда (проект № 17-78-20125). part-time jobs, overtime work and the use of previously accumulated material and financial assets. However, their own resources are gradually becoming less and less even among relatively prosperous representatives of the mass strata of the country's population. Therefore, the intensification of hired employment is becoming the only way to improve the financial situation for many Russians. An external barrier to its spread is the limited number of jobs that involve highly skilled and highly paid work and/or overtime pay.

Keywords: adaptation, population's resources, behavioral patterns, labor strategies, the impact of the crisis on society, adaptation strategies

Acknowledgments. The study was supported by a grant from the Russian Science Foundation (project No. 17-78-20125).

\section{Введение}

Социально-экономические потрясения 2020 г. нанесли мощный удар по благосостоянию и занятости россиян. По данным Росстата ${ }^{1}$, к концу III квартала уровень безработицы составил 6,3\%, тогда как в конце 2019 г. он был 4,6\%. Реальные располагаемые доходы россиян за 9 месяцев 2020 г. уменьшились на 4,3\%, и хотя

\footnotetext{
1 Уровень занятости населения в возрасте 15 лет и старше по субъектам Российской Федерации // Официальный сайт Росстата. URL: https://rosstat.gov.ru/storage/mediabank/xEwTeP4W/trud6_15-s.xls (дата обращения: 24.04.2021 г.)
} 
по итогам III квартала 2020 г. был зафиксирован рост начисленных заработных плат и пенсий на 2,6\%-2,8\%², другие виды выплат гражданам продолжили сокращаться. В итоге роста зарплат и пенсий было недостаточно, чтобы компенсировать падение уровня реальных доходов населения.

Сами россияне также фиксировали негативную динамику благосостояния своих домохозяйств. По данным общероссийского социологического опроса ФНИСЦ $\mathrm{PAH}^{3}$, проведенного в сентябре 2020 г. $(N=2000)$, к этому моменту у трети (35\%) взрослого населения страны сократились индивидуальные доходы, у половины семей, имеющих сбережения, была израсходована бо́льшая их часть, а у $38 \%$ выросли расходы на продукты питания и медикаменты. Что касается занятости, то каждый восьмой (12\%) взрослый россиянин потерял работу, 13\% респондентов оказались в неоплачиваемом отпуске или на грани увольнения, у 17 \% опрошенных возросла нагрузка на работе без увеличения оплаты труда. В условиях столь быстрых жизненных изменений россияне вынуждены были активизировать усилия по поддержанию своего материального благополучия. Анализу ответов на вопросы: «Каким образом в нынешних условиях пытаются поддержать свое материальное положение россияне?" и "Как выглядят их возможности в этой области?» посвящена данная статья.

\section{Теоретическая и эмпирическая базы исследования}

Существует несколько теоретических подходов к объяснению выбора индивидами действий по приспособлению к изменяющейся окружающей среде [Moen, Wethington, 1992; Allen, Henderson, 2016]. Один из них - структурный [Saraceno, 1989; Hareven, 1991; Bengtson, Allen, 2009] - предполагает, что действия человека по поддержанию и улучшению своего социально-экономического положения определяются внешними обстоятельствами: спецификой социальных институтов, доминирующими в общественном сознании ценностями и нормами и т. п. В отличие от структурного подхода, утверждающего приоритет внешней среды в процессах социально-экономической адаптации индивидов, теории рационального выбора [Becker, 1981; Berk, 1980; Coleman, 1986], наоборот, исходят из предпосылки, что все зависит от самих людей, которые для улучшения своего положения стремятся максимизировать отдачу от имеющихся у них материальных и нематериальных ресурсов. Третий подход, связанный с различными концепциями жизненного пути [Narotzky, Besnier, 2014], объединяет два предыдущих и основывается на идее, что индивиды выбирают стратегии поведения в соответствии со своими нормами, ожиданиями и располагаемыми ресурсами, которые, в свою очередь, определяются спецификой этапа их жизни, а также существующими в этот момент историческими, культурными и социальными условиями. Другими словами, люди максимизируют полезность имеющихся у них ресурсов, однако набор и ценность последних определяются этапом жизни человека, а также культурно-историческим и социально-экономическим контекстом.

\footnotetext{
2 Оперативный доклад за январь - сентябрь 2020 г. (Приложение 1) // Счетная палата РФ. 2020. 9 ноября. URL: https://ach.gov.ru/audit/9-mon-2020 (дата обращения: 21.04.2021).

3 На результатах этого опроса основано данное исследование.
} 
В большинстве отечественных исследований, посвященных адаптационным действиям россиян, признается ведущая роль индивидуального выбора способов поддержания или улучшения собственного материального благополучия [Шабанова, 2001; Ромм, 2002; Козырева, 2013; Авраамова, 2018; Каравай, 2019]. При этом авторы объясняют распространенность того или иного поведенческого паттерна в том числе и имеющимися в рассматриваемый исторический момент особенностями функционирования общественных институтов и российской экономики. В целом отечественные ученые сходятся во мнении, что обычно россияне склонны действовать рационально, максимизируя отдачу от имеющихся у них материальных и нематериальных ресурсов для улучшения своего материального положения с учетом особенностей институциональной среды. Однако акторы осуществляют свой выбор в условиях неполной или искаженной информации, зачастую неверно оценивая вероятность успешного исхода собственных действий, что ограничивает их рациональность ${ }^{4}$. В результате в процессе выбора они скорее определяют «практическую применимость такого поведения и его соответствие достижимому в данных условиях уровню удовлетворения потребностей" [Вольчик, Зотова, 2011: 55].

Отдельно стоит отметить, что адаптация может рассматриваться не только в том ключе, в котором мы ее анализируем в данной статье-как процесс выбора индивидом действий, способствующих достижению его целей [Козырева, 2013: 21]. Зачастую исследователи (например, [Беляева, 2001; Авраамова, 2018; Смолева, 2020]) изучают степень адаптации людей, оценивая ее как результат предпринимаемых действий. Индикаторами адаптированности к изменениям во внешней среде при этом могут выступать разнообразные показатели: объективные или субъективные оценки динамики материального и социально-экономического положения; степень удовлетворенности различными аспектами жизни, психоэмоциональное состояние и состояние здоровья в целом. Наконец, наличие устоявшегося набора действий, связанное с ним отсутствие необходимости предпринимать еще какие-либо шаги и позитивные оценки соответствующих показателей адаптированности также свидетельствуют об успешности процесса адаптации. Бездействие же при условии низких показателей адаптированности, напротив, говорит о дезадаптации индивида [Готлиб, 2000; Корель, 2005; Смолева, 2020].

Богатая на социально-экономические потрясения новейшая история России дала огромное количество материала для исследований, посвященных способам адаптации россиян к непрерывным изменениям во внешней среде. Ретроспективный анализ [Гордон, 1994; Lokshin, Yemtsov, 2001; Адаптационные стратегии..., 2003; Герасимова, 2005; Каравай, 2020] показал, что типичные поведенческие паттерны, широко распространенные в настоящее время, сформировались еще в 1990-е годы. Стремительная трансформация социальноэкономических институтов вынуждала россиян искать пути выживания, однако доступными для большинства из них оставались лишь способы, связанные с наращиванием активности на рынке труда или собственных приусадебных участках.

\footnotetext{
${ }^{4}$ Согласно теории ограниченной рациональности Г. Саймона, в реальности индивидам крайне сложно адекватно оценить вероятность успешности предпринимаемых ими действий, поскольку их прогнозы строятся исходя из предыдущего жизненного опыта (своего или других людей). Кроме того, недостаточно полная или искаженная информация, сложившиеся привычки и предубеждения могут приводить к тому, что человек выбирает наиболее удобные для него, но не оптимальные для достижения поставленной цели действия. Подробнее см.: [Simon, 1959].
} 
В тот период появились и новые возможности, связанные с получением ренты от частной собственности или предпринимательством, но они не получили широкого распространения.

Рост благосостояния россиян, наблюдавшийся в первой половине 2000-х годов, не привел к появлению новых способов улучшения материального благополучия, однако поведение части населения все же изменилось: выросла доля тех, кто ничего не предпринимал для изменения своего финансового положения, поскольку был удовлетворен им [Каравай, 2020]. Со второй половины 2000-х годов пассивная в отношении улучшения своего материального благополучия часть населения остается практически неизменной и составляет около трети массовых слоев общества. Причины этой пассивности неоднократно изменялись с течением времени и в зависимости от экономической ситуации, на что уже обращалось внимание в литературе [там же]. Однако пока не проводился анализ того, как последний экономический кризис сказался на спектре действий россиян по улучшению собственного материального положения и в каком состоянии возможности для них находились к началу 2020 г.

Эмпирической базой нашего исследования, посвященного именно этим сюжетам, стали данные опросов Института социологии ФНИСЦ РАН, проведенных весной 2018 г. и осенью 2020 г. ${ }^{5}$ Кроме того, в отдельных случаях мы использовали данные, собранные Институтом социологии ФНИСЦ РАН в 2015 г. ${ }^{6}$ - в разгар предыдущего экономического кризиса, а также в 2013 г. ${ }^{7}$ Это позволило сравнить поведение россиян в кризисных условиях в разные периоды и выявить специфику, присущую текущему этапу. Наконец, для анализа долгосрочных трендов мы опирались на исследования Института социологии ФНИСЦ РАН, проведенные в 2003 и 2008 гг. ${ }^{8}$ Во всех указанных исследованиях принципы построения многоступенчатой стратифицированной случайной выборки были идентичны и репрезентировали население страны от 18 лет и старше по регионам, а внутри них - по полу, возрасту и типу поселения. Опрос во всех случаях, в том числе и в 2020 г., проводился при личном интервьюировании респондентов.

Все массивы данных, на которых основывается наше исследование, содержали вопрос «Каким образом Вы или члены Вашей семьи пытаетесь изменить свое материальное положение в лучшую сторону?». Набор вариантов ответа из года в год не менялся и включал вариант "другое (что именно?)", при этом за рассматриваемый период альтернативные варианты если и возникали, то широкого распространения не получили. Кроме того, перечень закрытий предполагал варианты "ничего не предпринимаю, так как в этом нет необходимости" и "ничего не предпринимаю, так как ничего не могу сделать для улучшения своего положения". Это позволило определить причины бездействия респондентов в отношении улучшения их материального положения.

\footnotetext{
5 Восьмая (март 2018 г., N=4000) и десятая (сентябрь 2020 г., $N=2000$ ) волны мониторинга Института социологии ФНИСЦ РАН.

6 Третья волна мониторинга Института социологии ФНИСЦ РАН (октябрь 2015 г., N=4000).

7 Исследование "Бедность и бедные в современной России", март 2013 г. $(N=1600)$.

8 Исследование «Богатые и бедные в современной России", март 2003 г. (N=2106); Исследование "Малообеспеченные в современной России: кто они? Как живут? К чему стремятся?", июнь 2008 г. (N=1717).
} 


\section{Распространенность среди россиян различных действий по улучшению своего материального положения}

Как мы уже упоминали выше, с конца 2000-х годов доля не предпринимающих никаких действий по улучшению своего материального положения россиян практически не менялась и составляла $34 \%$-36 \% взрослого населения. Другими словами, большая часть россиян, независимо от экономической ситуации в стране, обычно предпочитает использовать те или иные способы улучшения собственного материального положения. При этом нельзя сказать, что эти способы у активной части населения разнообразны - из всего предложенного набора, включавшего двенадцать действий (в том числе вариант "другое»), в среднем россияне одновременно практиковали менее двух (среднее их количество в каждом из опросов составляло около 1,7, а медиана была неизменно равна 1).

Россиян, ничего не предпринимавших для улучшения собственного материального положения, в зависимости от их субъективных ощущений и обстоятельств жизни можно разделить на две подгруппы: "добровольно" и "Вынужденно" бездействующих. Первые ничего не предпринимали, поскольку не видели в этом необходимости. С точки зрения теории они успешно завершили процесс адаптации [Корель, 2005], поскольку «набрали" определенный набор действий, необходимых для поддержания своего материального положения на устраивающем их уровне, что проявлялось в том, что они сравнительно чаще остальных оценивали его как хорошее или были им удовлетворены (как плохое его оценивали в этой группе только 10\%). “Вынужденно” бездействующие, наоборот, не видели возможностей улучшить свое материальное положение, хотя наверняка искали их, поскольку чаще остальных негативно оценивали не только сегодняшнее его состояние (36\%), но и прошлую динамику своего материального положения не менее чем в половине случаев (53\%). Это позволяет охарактеризовать таких "вынужденно" бездействующих как дезадаптантов [Готлиб, 2000]. Данные свидетельствуют, что с 2013 г. доля дезадаптантов в массовых слоях российского общества находилась в диапазоне $20 \%-24 \%$ (см. рис. 1), что говорит об отсутствии почти у четверти россиян ресурсов для успешной адаптации к неблагоприятным внешним условиям. "Добровольно" бездействующие - это, напротив, обычно наиболее благополучные представители массовых слоев населения, накопившие достаточно материальных и нематериальных ресурсов [Каравай, 2019] и в целом удовлетворенные своим положением. Не случайно, по данным 2018 г., среди довольных собственным материальным положением россиян половина предпочитала ничего не предпринимать для его улучшения. Однако к осени 2020 г. соответствующий показатель сократился до $35 \%$. Численность "добровольно" бездействующих респондентов в целом уменьшилась с 17 \% в 2018 г. до 12\% к осени 2020 г. Это говорит о том, что, сравнивая себя с другими, многие считают свое положение в нынешних условиях хорошим, однако поддержание его на привычном уровне требует от них активизации усилий. В то же время в разгар предыдущего кризиса, весной 2015 г., число удовлетворенных своим материальным положением россиян также уменьшилось, однако существенного сокращения группы "добровольно" бездействующих не произошло (16\% - в 2013 г. и 15\% - в 2015 г.), то есть положение тех, чьи запросы соответствовали возможностям их удовлетворения, ухудшилось тогда в меньшей 
степени, чем в настоящее время. Все это свидетельствует о том, что в эпоху пандемии негативные процессы, происходящие в экономике, как никогда ранее сильно повлияли на поведение индивидов, прежде считавшихся адаптированными к реалиям современной России, поэтому части из них пришлось начать предпринимать активные действия по улучшению своего материального положения.

—«Добровольно» бездействующие -——Вынужденно» бездействующие

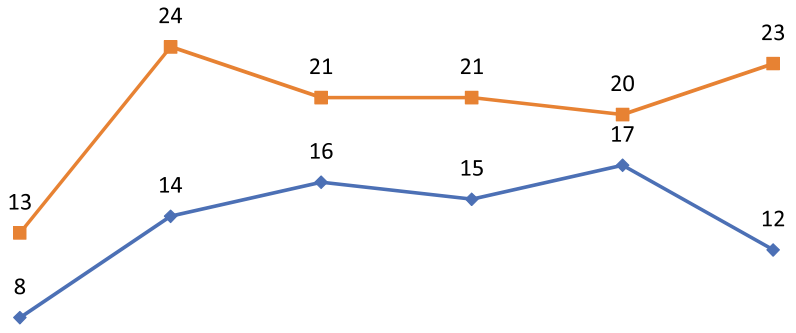

2003

2008

2013

2015

2018

2020

Рис. 1. Динамика численности "добровольно" и "вынужденно" бездействующих в отношении улучшения собственного материального положения россиян (в \%) ${ }^{9}$

Рассмотрим теперь другую часть россиян, проявляющих активность для улучшения собственного материального положения ${ }^{10}$. В зависимости от того, какие ресурсы используют индивиды, весь перечень выбираемых ими действий можно условно разделить на четыре группы:

1) действия, связанные с рынком труда: увеличение нагрузки на основной работе, поиск дополнительной постоянной занятости и/или временных приработков, переквалификация с целью занять более привлекательную профессиональную позицию;

2) действия, связанные с использованием накопленных материальных ресурсов: "проедание" имеющихся денежных накоплений, продажа или сдача в аренду недвижимости или товаров длительного пользования, использование продуктов личного приусадебного хозяйства для собственного потребления или на продажу;

3) действия, связанные с привлечением внешних ресурсов: увеличение долговой нагрузки, использование помощи других людей;

4) действия, направленные на подготовку к миграции или эмиграции.

В предыдущих исследованиях было показано, что выбор тех или иных действий для улучшения своего материального положения в значительной степени зависит от имеющихся у индивида ресурсов [Авраамова, Логинов, 2002; Козырева, 2013;

\footnotetext{
9 По данным опросов Института социологии ФНИСЦ РАН.

${ }^{10}$ Далее, говоря о тех, кто что-либо предпринимал для улучшения своего материального положения, мы будем условно называть их «активной" частью россиян.
} 
Каравай, 2019]. Следовательно, изменения в наличии или объеме тех или иных ресурсов повлияют на поведение людей. Будут оказывать воздействие на это поведение и внешние институциональные условия, обуславливающие возможности индивидов практиковать те или иные действия.

Данные свидетельствуют, что ориентированные на рынок труда стратегии улучшения материального положения уже долгое время остаются наиболее распространенными. Такого рода действия и в 2018, и в 2020 гг. встречались более чем у двух третей “активных" россиян. В то же время, как показано на рисунке 2, характер этих действий изменился. Если в 2018 г. использование любых разовых приработков для повышения материального благополучия практиковали $40 \%$ "активных" россиян (58\% среди практиковавших действия, ориентированные на рынок труда), то в 2020 г.- только 33\% (49\% среди практиковавших действия, ориентированные на рынок труда). Это связано, видимо, со “схлопыванием» рынка услуг из-за минимизации социальных контактов во время пандемии, а также с падением доходов населения. Несколько сократилось и количество россиян, которые для поддержания своего материального положения практиковали только разовые приработки - с $15 \%$ до $11 \%$ "активного" населения ${ }^{11}$. Перераспределение произошло в пользу более устойчивых форм занятости: постоянной множественной и сверхурочной на основной работе.

Увеличилась и доля стремящихся изменить свое положение на рынке труда через переквалификацию. При этом представители молодежи до 25 лет почти в четыре раза чаще, чем в 2018 г., стали рассматривать переквалификацию в качестве способа улучшить свое материальное положение (11\% вместо 3 \% выбирающих активную модель поведения молодых людей соответствующего возраста). В когорте 26-35-летних, напротив, расширилась практика интенсификации постоянной занятости. Учитывая сложности с трудоустройством молодежи до 25 лет и востребованность на рынке труда работников 26-35 лет, это означает усиление соответствующих тенденций в ходе нынешнего экономического кризиса.

Как показывают предыдущие исследования, сравнительно чаще дополнительную постоянную занятость выбирают лица с высоким качеством человеческого капитала ${ }^{12}$ (в случае рабочих - имеющие не менее пятого разряда), причем у этой наиболее квалифицированной части работников физического и нефизического труда сокращается доля использовавших другие возможности для сохранения своего привычного уровня жизни. Так, за последние 2,5 года в составе "активных" россиян с четверти до трети выросла доля тех, кто пытается улучшить свое материальное положение только с помощью постоянной дополнительной занятости и не предпринимает ничего более, то есть другие действия для представителей наиболее квалифицированных работников, видимо, менее эффективны, а для кого-то, возможно, и недоступны.

\footnotetext{
${ }^{11}$ Сокращение произошло в большой степени за счет отказа молодежи от таких действий. Так, если в 2018 г. использовали любую возможность для заработков 50\% лиц до 25 лет и 40\% лиц 26-35 лет, то осенью 2020 г. соответствующие показатели сократились до $38 \%$ и $32 \%$ соответственно.

12 Обучавшиеся не менее 15 лет, владеющие иностранными языками и использующие информационные технологии в повседневной жизни, а также включенные в процессы непрерывного образования. Подробнее см.: [Тихонова, Каравай, 2017].
} 
УВЕЛИЧЕНИЕ ТРУДОВЫХ НАГРУЗОК

Используют любую возможность разовых и временных приработков

Работают сверхурочно или по совместительству по основному месту работы

Работают по совместительству в нескольких местах на постоянной основе

Переквалифицируются, чтобы сменить работу

ИСПОЛЬЗОВАНИЕ ИМЕЩИХСЯ АКТИВОВ

Обеспечивают себя сами некоторыми продуктами питания

Сдают внаем недвижимость, автомобиль и т.п. и/или используют проценты от сбережений

Торгуют самостоятельно выращенными продуктами

Распродают кое-что из накопленного имущества

ПРИВЛЕЧЕНИЕ ВНЕШНИХ РЕСУРСОВ

Получают помощь со стороны родственников, друзей, знакомых

Вынуждены занимать деньги

ЭМИГРАЦИЯ

Готовятся уехать за рубеж
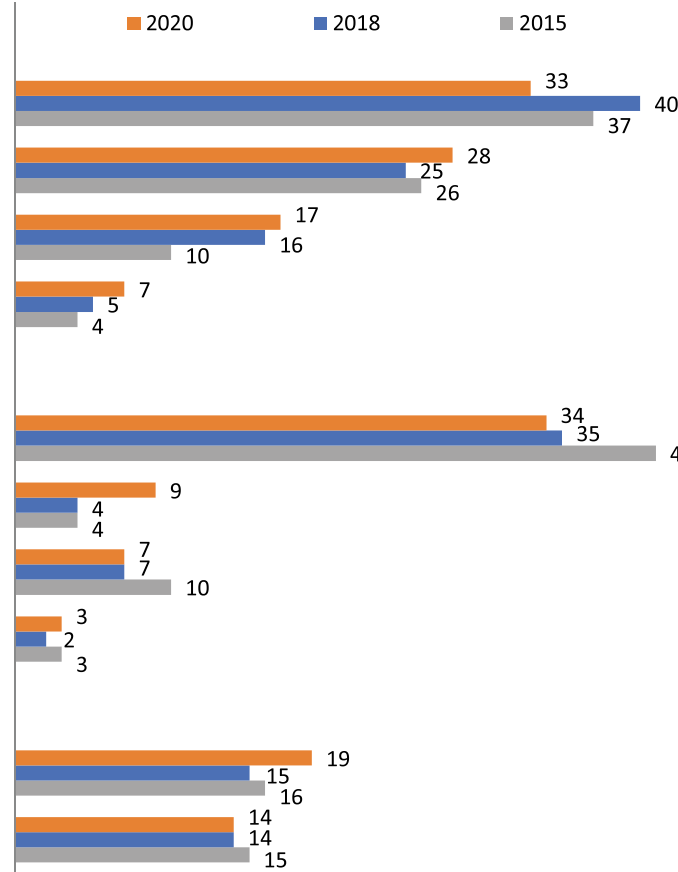

Рис. 2. Динамика распространенности действий по улучшению материального положения (в \% от что-либо предпринимавших $)^{13}$

Неоднозначна ситуация с таким "универсальным" для россиян способом выживания в трудные времена, как выращивание продуктов на приусадебных, садовых и т. п. участках. Несмотря на то, что данный способ поддержания материального положения в 2020 г. использовался третью “активных" россиян, в масштабах страны это сравнительно немного (если говорить о россиянах в целом, включая и "пассивную" их часть, то всего 20 \%). Кроме того, наше и другие исследования [Воронин и др., 2020: 85] фиксируют постепенное сокращение числа сторонников таких действий с начала 2000-х годов. Так, в 2003 г. доля сторонников поддержания своего материального положения за счет продукции с приусадебных и т. п. участков составляла 58 \% активного населения, а к 2018 г. этот показатель сократился до $35 \%$. Причем этот способ теряет популярность даже среди людей старшего возраста и сельских жителей. Это происходит в том числе из-за продолжающегося процесса "обезземеливания" последних. Так, за период с 2008 по 2018 г. доля владеющих земельными участками сельчан сократилась с $55 \%$ до $48 \%$.

\footnotetext{
${ }_{13}^{13}$ По данным опросов Института социологии ФНИСЦ РАН.
} 
Выше мы уже говорили о том, что многим представителям относительно благополучных слоев, которые обычно довольны своим материальным положением и поэтому предпочитают бездействовать в отношении его улучшения, в 2020 г. пришлось изыскивать дополнительные источники доходов. В условиях ограниченных возможностей для активизации занятости это стало причиной двукратного роста числа россиян, использующих накопленные ранее сбережения. По оценкам самих россиян, практически каждому шестому из них в течение первых трех кварталов 2020 г. пришлось потратить бо́льшую часть (или все) сбережений семьи. Динамика субъективных оценок наличия сбережений показывает, что доля имеющих какие-либо накопления россиян падала в течение последних пяти лет: в 2015 г. сбережения имели 33 \%, в 2018 году - 30\%, в 2020 г.-28\%. Статистика ЦБ РФ также свидетельствует о падении темпов прироста средне- и долгосрочных вкладов в российских банках, начиная с марта 2020 г. ${ }^{14}$ В итоге возможности россиян из высокоресурсных слоев поддерживать приемлемый уровень доходов за счет имеющихся накоплений сокращаются уже более пяти лет, причем текущий кризис ускорил эти процессы.

Последнее, о чем нам осталось упомянуть, обозначая тенденции изменений поведения россиян в связи с текущим кризисом,- это рост доли населения, прибегающего к внешней помощи с целью поддержания своего материального благополучия. Этот рост произошел не за счет тех, кто для улучшения материального положения прибегал к наращиванию долговой нагрузки,- их доля в составе "активных" россиян в течение последних пяти лет остается на уровне $14-15 \%{ }^{15}$, а за счет тех, кто для этих целей стал обращаться к близким и родным, - таких в 2020 г. по сравнению с 2018 г. стало сравнительно больше, а их медианный возраст вырос с 37 до 39 лет.

Возможность пользоваться внешней помощью имеется, однако далеко не у всех россиян, а лишь у тех, чье окружение имеет для этого ресурсы. Как показано на рисунке 3, даже на фоне наиболее благополучной в плане ресурсообеспеченности ее представителей группы "добровольно" бездействующих, у сторонников получения внешней помощи по некоторым ее видам ситуация выглядела лучше, что и позволяло им активно использовать данный ресурс. Так, их социальное окружение чаще, чем у остальных, могло помочь пережить временные трудности за счет небольших займов, помощи в поиске разовых приработков и даже в устройстве на хорошую работу.

Таким образом, используют ресурс своих социальных сетей прежде всего люди, которые этот ресурс имеют. Однако таких среди россиян оказывается уже не больше половины, хотя в целом для населения нашей страны всегда было свойственно обращаться к социальному ресурсу в сложных жизненных ситуациях, в частности

\footnotetext{
${ }^{14}$ Банковский сектор в сентябре: неоднородная динамика кредитования // О чем говорят тренды? Макроэкономика и рынки. Бюллетень Департамента исследований и прогнозирования ЦБ РФ. Ноябрь 2020. № 7. C. 35-40. URL: https://www.cbr.ru/Collection/Collection/File/31429/bulletin_20-07.pdf (дата обращения: 01.12.2020).

${ }^{15}$ Речь идет не о всех россиянах, которые прибегают к заемным средствам для покупки необходимых товаров, включая и недвижимость (их доля в 2018 г. составляла $42 \%$, а в 2020 г.- 45\%), а именно о той части населения, представители которой рассматривают наращивание долговой нагрузки как способ поддержать приемлемый уровень жизни, зачастую в условиях отсутствия для этого других возможностей, кроме как занять денег "до получки" у близкого окружения.
} 
в момент потери занятости и поиска новой работы [Авраамова, Логинов, 2002; Козырева, 2013].

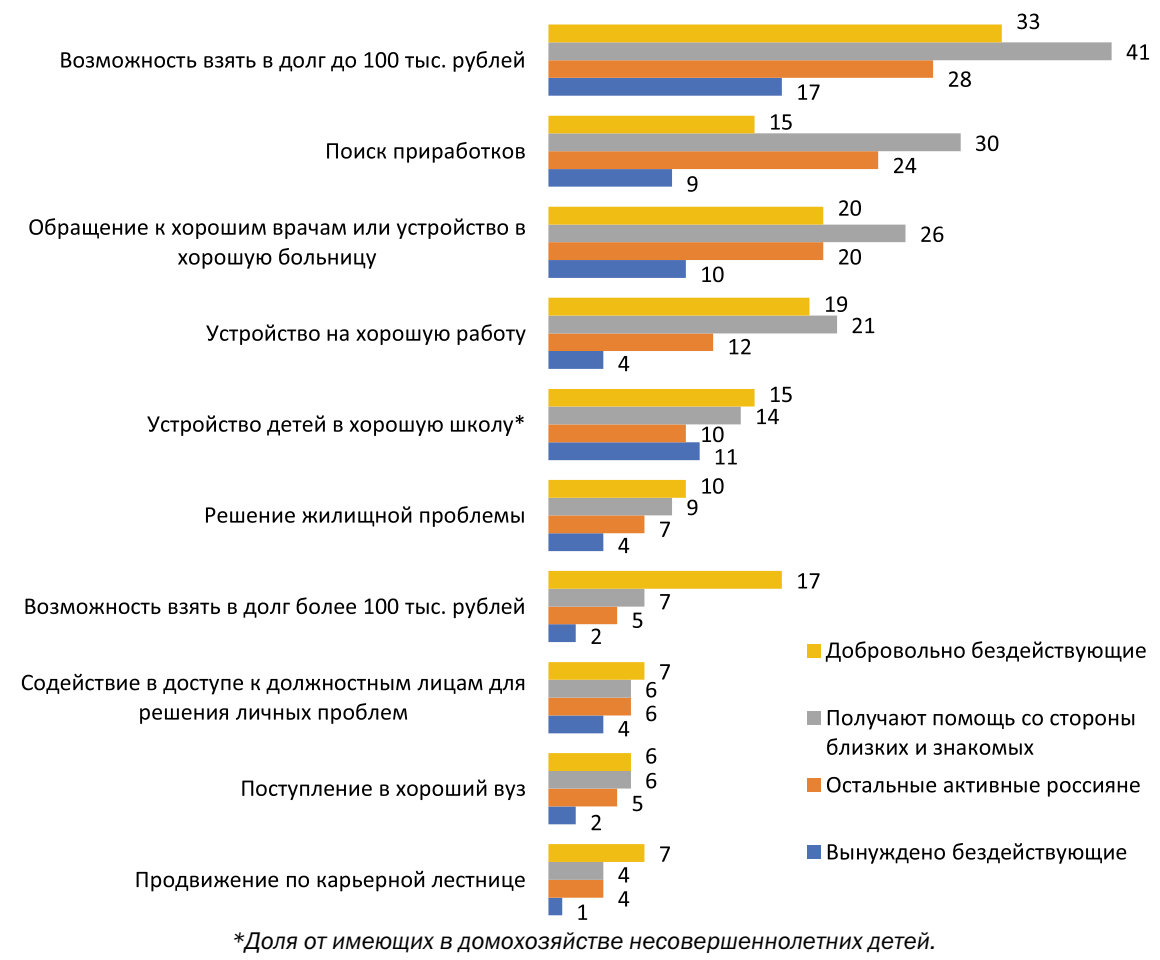

Рис. 3. Распространенность возможности получить различные виды помощи среди получающих ее от ближнего окружения, а также среди “добровольно" и "вынужденно" бездействующих (в \%) ${ }^{16}$

Напомним также, что в теории социальный капитал принято разделять на два вида: замыкающий (эксклюзивный), связанный с родственными, неформальными и другими связями в группах, гомогенных по тем или иным основаниям, и связующий (инклюзивный), включающий межгрупповые контакты [Woolcock, 1998; Putnam, 2001]. Последний напрямую связан с уровнем доверия в обществе. Если с учетом этого посмотреть на распределение оценок в вопросах о распространенности доверия и взаимопомощи в российском обществе, то видно, что пока существует определенного рода паритет между теми, кто говорит о дефиците доверия ${ }^{17}$ и индивидуализме россиян ${ }^{18}$, и теми, кто склоняется к другому полюсу оценок. Осенью 2020 г. половина массовых слоев населения оценивала на пять баллов из десяти возможных и уровень доверия в обществе, и склонность людей к взаимопомощи, однако при этом только четверть россиян ставили соответствую-

\footnotetext{
16 По данным опроса Института социологии ФНИСЦ РАН, 2020 г.

17 Шкала: “Большинству людей сегодня можно доверять” (10 баллов) / “Осторожность в доверии не помешает” (1 балл).

18 Шкала: "Люди стараются помогать другим" (10 баллов) / "Люди чаще всего заботятся только о себе” (1 балл).
} 
щие оценки выше шести баллов. Кроме того, по субъективным оценкам россиян, ситуация с доверием в российском обществе с годами ухудшается. Дополнительно осложнила эту ситуацию пандемия: мнение, что уровень доверия в течение II и III кварталов 2020 г. снизился, высказывала в сентябре 2020 г. половина (49\%) взрослого населения, и только 7 \% считали, что этот показатель вырос.

Таким образом, на данный момент связующий социальный капитал имеет тенденцию к сокращению, в то время как ситуация с замыкающим социальным капиталом противоречива, но в целом тоже не очень благополучна. Дальнейшее развитие событий в таком русле может привести к тому, что российское общество постепенно фрагментируется на группы, не связанные друг с другом, причем вне этих групп окажутся многие россияне, зачастую лишенные других видов ресурсов (на данный момент таких половина). Все это, в свою очередь, будет тормозить не только социальную мобильность, но и развитие экономики, поскольку для ее роста социальный капитал имеет большое значение [Westloong, Adam, 2010].

\section{Заключение}

Сложившиеся у россиян в 1990-е годы поведенческие паттерны, обеспечивающие относительную стабильность или даже улучшение их материального положения, сохраняли свою значимость и в последующие десятилетия новейшей истории России. Несмотря на то, что постепенно в них происходят и накапливаются определенные изменения, к концу второй декады XXI века наиболее распространенными действиями среди россиян, предпочитающих что-либо предпринимать для поддержания своего материального положения, по-прежнему оставались случайные заработки и работа на приусадебных участках. Эти действия "универсальны" в том смысле, что они характерны для представителей любых слоев общества, но в первую очередь их практикуют те, кто входит в наиболее уязвимые социальные группы, поскольку другие способы улучшения материального положения для них недоступны. При этом все меньшее количество россиян практикуют в последние годы как выращивание продуктов, все еще остающееся значимой составляющей в "стратегиях выживания" жителей сельской местности и малых городов, так и разовые приработки, поддерживающие материальное положение представителей низкоресурсных слоев населения в крупных городах. Не последнюю роль в этих процессах сыграли изменения на рынке труда, выраженные в повышении трудовых нагрузок у всех работающих, и сокращение доли собственников земли в сельской местности.

Снижение уровня реальных доходов населения в 2020 г. привело к тому, что в ходе текущего кризиса впервые за сравнительно длительное время многим из тех жителей страны, кто, как казалось, успешно адаптировался к сложившимся в современной России «правилам игры", пришлось предпринимать действия по "спасению" привычного уровня своего материального благосостояния. В итоге по сравнению с 2018 г. доля "добровольно бездействующих" сократилась на 30\%, хотя до этого она с 2003 г. росла небольшими темпами. Одновременно увеличилась доля дезадаптантов, то есть тех, кто не сумел приспособиться к сложившимся институциональным условиям, но выросла она относительно меньше - на $15 \%$. Вероятно, свою роль здесь сыграли беспрецедентные меры социальной под- 
держки уязвимых слоев населения, предпринимавшиеся российскими властями в наиболее острый период пандемии COVID-19.

Следствием описанных выше процессов стало не только изменение структуры группы "пассивных" россиян, но и то, что группа активно действующей в отношении поддержания своего материального положения части населения пополнилась представителями сравнительно благополучных и высокоресурсных социальных слоев. Это привело к большему распространению среди "активных" россиян действий, которые предполагают использование накопленных ранее материальных и нематериальных ресурсов,- расходование сбережений, получение рентных платежей от сданной в аренду недвижимости, обращение к помощи ближнего окружения и т.д., то есть использование внешних ресурсов. Для менее обеспеченных групп граждан доступными остались только те адаптационные действия, которые связаны с постоянной занятостью: осенью 2020 г. стало больше тех, кто для поддержания материального положения стал наращивать трудовые нагрузки на одном или нескольких местах постоянной работы, однако экономически эффективной эта стратегия являлась, видимо, в основном для высококвалифицированной части населения.

Таким образом, основные изменения в адаптационном поведении россиян выражались к концу 2020 г. в том, что многим наиболее благополучным из них приходилось тратить накопленные ранее ресурсы, восполнение которых в условиях пандемии и вызванного ею экономического кризиса представляет нелегкую задачу. Виной тому и падение реальных доходов населения, что препятствует восстановлению потраченных в течение 2020 г. сбережений, и сокращение и без того ограниченного количества рабочих мест, предполагающих высокие заработные платы и оплату сверхурочной занятости, и общий рост безработицы, и истощение социального капитала как на микроуровне, так и в обществе в целом.

\section{Список литературы (References)}

Адаптационные стратегии населения / под ред. Авраамовой Е. М. СПб. :ИСЭПН PAH, 2003.

Avraamova E. M. (ed.) (2003) Adaptation Strategies of the Population. Saint Petersburg: ISESP RAS. (In Russ.)

Авраамова Е. М. Российское население в постсоветский период: опыт кризисов и социальные ресурсы развития. М.: Дело, 2018.

Avraamova E. M. (2018) Russian Population in the Post-Soviet Period: An Experience of Crises and Social Resources of Development. Moscow: Delo. (In Russ.)

Авраамова Е. М., Логинов Д. М. Адаптационные ресурсы населения: попытка количественной оценки // Мониторинг общественного мнения: экономические и социальные перемены. 2002. № 3. С. 13-17.

Avraamova E. M., Loginov D. M. (2002) Adaptation Resources of the Population: An Attempt to Quantify. Monitoring of Public Opinion: Economic and Social Changes. No. 3. P. 13-17. (In Russ.)

Беляева Л.А. Идеально типические группы адаптации в современной России // Кто и куда стремится вести Россию? Акторы макро, мезо и микроуровней современно- 
го трансформационного процесса / под общ. ред. Т. И. Заславской. М. : МВШСЭН. 2001. C. $327-333$.

Belyaeva L. A. (2001) Ideally Typical Groups of Adaptation in Modern Russia. In: Zaslavskaya T.I. (ed.) Who Aspires to Lead Russia and Where to? Actors of Macro-, Meso- and Micro- Levels of the Contemporary Transformation Process. Moscow: MSSES. P. 327-333. (In Russ.)

Вольчик В.В., Зотова Т. А. Адаптивная рациональность и экономическое поведение в эволюционном контексте //Terra Economicus. 2011. T. 9. № 4. С. 54-64. Vol'chik V.V., Zotova T. A. (2011) Adaptive Rationality and Economic Behavior in an Evolutionary Context. Terra Economicus. Vol. 9. No. 4. P. 54-64. (In Russ.)

Воронин Г. Л., Киселева И. П., Козырева П. М., Косолапов М. С., Низамова А. Э., Сивкова И.В., Смирнов А.И., Соколова С.Б., Тонис Е.И., Евграфова К. О. Российские домохозяйства: экономическое поведение, положение на рынке труда, социальное самочувствие (по данным РМЭЗ НИУ ВШЭ 1994-2018 гг.) // Вестник Российского мониторинга экономического положения и здоровья населения НИУ ВШЭ (RLMS-HSE). 2020. Вып. 10. / отв. ред. П. М. Козырева. М. : Нац. исслед. ун-т "Высшая школа экономики". С. 7-94. URL: https://online.fliphtml5.com/vgiyk/ hwgy/\#p=6 (дата обращения: 26.04.2021).

Voronin G. L., Kiseleva I. P., Kozyreva P. M., Kosolapov M.S., Nizamova A. E., Sivkova I. V., Smirnov A. I., Sokolova S. B., Tonis E. I., Evgrafova K. O. (2020) Russian Households: Economic Behavior, Position On The Labor Market, Social Well-Being (RLMS-HSE, 1994-2018). In: Kozyreva P. M. (ed.) Bulletin of the Russian Longitudinal Monitoring Survey. M.: HSE University. URL: https://online.fliphtml5.com/vgiyk/hwgy/\#p=6 (accessed: 26.04.2021). (In Russ.)

Герасимова С.Б. Стратегии выживания семей в условиях рыночной экономики //Изучение проблем бедности в России. М.: Алекс. 2005. С. 190-206.

Gerasimova S. B. (2005) Family Survival Strategies in a Market Economy. In: Study of Poverty in Russia. Moscow: Alex. P. 190-206. (In Russ.)

Гордон Л. А. Социальная адаптация в современных условиях / Социологические исследования. 1994. № 8. С. 3-15.

Gordon L. A. (1994) Social Adaptation in Modern Conditions. Sociological Studies. No. 8. P. 3-15. (In Russ.)

Готлиб А. С. Социально-экономическая адаптация россиян: опыт сочетания количественной и качественной методологии в одном отдельно взятом исследовании // Социология: методология, методы, математическое моделирование (Социология: 4M). 2000. № 12. C. 5-24. URL: https://www.fnisc.ru/index.php?page_ $i d=2384 \& i d=3935 \& l=\& j=6$ (дата обращения: 26.04.2021).

Gotlib A.S. (2001) Socio-Economic Adaptation of Russians: Experience of Combining Quantitative and Qualitative Methodology in One Single Study. Sociology: Methodology, Methods, Mathematical Modeling (Sotsiologiya: 4M). No. 12. P. 5-24. URL: https:// www.fnisc.ru/index.php?page_id=2384\&id=3935\&l=\&j=6 (accessed: 26.04 .2021$)$. (In Russ.) 
Каравай А. В. Основные модели социально-экономической адаптации в разных стратах российского общества // Terra Economicus. 2019. Т. 17. № 3. С. 128-145. https://doi.org/10.23683/2073-6606-2019-17-3-128-145.

Karavay A. V. (2019) Basic Models of Socio-Economic Adaptation in Different Strata of Russian Society. Terra Economicus. Vol. 17. No. 3. P. 128-145. https://doi. org/10.23683/2073-6606-2019-17-3-128-145. (In Russ.)

Каравай А. В. Изменения в стратегиях социально-экономической адаптации россиян в конце XX-начале XXI вв. // Журнал институциональных исследований. 2020. T. 12. № 1. C. 144-159. https://doi.org/10.17835/2076-6297.2020.12.1.144-159. Karavay A. V. (2020) Changes in the Russians' Strategies of Socio-Economic Adaptation in the Late XX - Early XXI Centuries. Journal of Institutional Studies. Vol. 12 No. 1. P. 144-159. https://doi.org/10.17835/2076-6297.2020.12.1.144-159. (In Russ.)

Козырева П. М. Ресурсы и практики социально-экономической адаптации населения России. М.: Новый хронограф, 2013.

Kozyreva P. M. (2013) Resources and Practices of Socio-Economic Adaptation of the Russian Population. Moscow: New Chronograph. (In Russ.)

Корель Л. В. Социология адаптаций: вопросы теории, методологии и методики. Новосибирск: Наука, 2005.

Korel L. V. (2005) Sociology of Adaptation: Problems of Theory, Methodology and Technique. Novosibirsk: Nauka. (In Russ.)

Ромм М.В. Адаптация личности в социуме: Теоретико-методологический аспект. Новосибирск, 2002.

Romm M. V. (2002) Adaptation of Personality in Society: Theoretical and Methodological Aspect. Novosibirsk. (In Russ.)

Смолева Е. О. Социальная адаптация, социальный капитал и здоровье населения Вологодской области // Мониторинг общественного мнения: экономические и социальные перемены. 2020. № 4. С. 136-161. https://doi.org/10.14515/ monitoring.2020.4.983.

Smoleva E. O. (2020) Social Adaptation, Social Capital and Population Health in the Vologda region. Monitoring of Public Opinion: Economic and Social Changes. No. 4. P. 136-161. https://doi.org/10.14515/monitoring.2020.4.983. (In Russ.).

Тихонова Н.Е., Каравай А. В. Человеческий капитал российских рабочих: общее состояние и специфические особенности / Мир России. 2017. Т. 26. № 3. С. 6-35. https://doi.org/10.17323/10.17323/1811-038X-2017-26-3-6-35.

Tikhonova N.E, Karavay A. V. (2017) The Human Capital of Russian Workers: The Overall State and Its Specifics. Universe of Russia. Vol. 26. No. 3. P. 6-35. URL: https://doi. org/10.17323/10.17323/1811-038X-2017-26-3-6-35. (In Russ.)

Шабанова М. А. Массовые адаптационные стратегии и перспективы институциональных трансформаций // Мир России. 2001. T. 10. № 3. C. 78-104. URL: https:// mirros.hse.ru/article/view/5341 (дата обращения: 26.04.2021).

Shabanova M. A. (2001) Mass Adaptation Strategies and Prospects of Institutional Transformations. Universe of Russia. Vol. 10. No. 3. P. 78-104. https://mirros.hse. ru/article/view/5341 (accessed: 26.04.2021). (In Russ.) 
Allen K. R., Henderson A. C. (2016) Family Theories: Foundations and Applications. Hoboken, NJ: Wiley.

Becker G. S. (1981). A Treatise on the Family. Cambridge, MA: Harvard University Press. Bengtson V. L., Allen K. R. (2009) The Life Course Perspective Applied to Families over Time. Sourcebook of Family Theories and Methods. In: Sourcebook of Family Theories and Method. Boston, MA: Springer. P. 469-504. https://doi. org/10.1007/978-0-387-85764-0_19.

Berk R. A. (1980) The New Home Economics: An Agenda for Sociological Research. In: Berk S. F. Women and Household Labor. Beverly Hills, CA: Sage. 1980. P. 113-148.

Coleman J.S. (1986) Social Theory, Social Research, and a Theory of Action. American Journal of Sociology. Vol. 91. No. 6. P. 1309-1335. URL: https://www.journals.uchicago.edu/doi/abs/10.1086/ajs.91.6.2779794 (accessed: 26.04.2021).

Narotzky S., Besnier N. (2014) Crisis, Value, and Hope: Rethinking the Economy. Current Anthropology. Vol. 55. No. S9. P. S4-S16. https://doi.org/10.1086/676327.

Hareven T.K. (1991) The History of the Family and the Complexity of Social Change. The American Historical Review. Vol. 96. No. 1. P. 95-124. https://doi.org/10.1086/ ahr/96.1.95.

Lokshin M., Yemtsov R. (2001) Household Strategies for Coping With Poverty and Social Exclusion in Post-Crisis Russia. Policy Research Working Papers. The World Bank. https://doi.org/10.1596/1813-9450-2556.

Moen P., Wethington E. (1992) The Concept of Family Adaptive Strategies. Annual Review of Sociology. Vol. 18. No. 1. P. 233-251. https://doi.org/10.1146/annurev. so.18.080192.001313.

Putnam R. (2001) Social Capital: Measurement and Consequences. Canadian Journal of Policy Research. No. 2. P. 41-51.

Saraceno C. (1989) The Concept of Family Strategy and Its Application to the FamilyWork Complex: Some Theoretical and Methodological Problems. Marriage \& Family Review. Vol. 14. No. 1-2. P. 2-18. https://doi.org/10.1300/j002v14n01_01.

Simon H. A. (1959) Theories of Decision-Making in Economics and Behavioral Science. The American Economic Review. Vol. 49. No. 3. P. 253-283. URL: https://www.jstor. org/stable/1809901 (accessed: 26.04.2021).

Woolcock M. (1998) Social Capital and Economic Development: Toward a Theoretical Synthesis and Policy Framework. Theory and Society. Vol. 27. No. 2. P. 151-208. https://doi.org/10.1023/A:1006884930135.

Westlund H., Adam F. (2010) Social Capital and Economic Performance: A MetaAnalysis of 65 Studies. European Planning Studies. Vol. 18. No. 6. P. 893-919. https://doi.org/10.1080/09654311003701431. 